\title{
Number of Resected Lymph Nodes and Survival of Patients with Locally Advanced Esophageal Squamous Cell Carcinoma Receiving Preoperative Chemoradiotherapy
}

\author{
JHE-CYUAN GUO ${ }^{1,2,3}$, CHIA-CHI LIN ${ }^{1,4}$, TA-CHEN HUANG ${ }^{1,4}$, PEI-MING HUANG ${ }^{5,6}$, \\ HUNG-YANG KUO ${ }^{7}, \mathrm{CHIN}-\mathrm{HAO}_{\mathrm{CHANG}}{ }^{2}, \mathrm{CHIA-CHUN} \mathrm{WANG}^{1,3}, \mathrm{JASON}^{\mathrm{CHIA}-H S I E N ~} \mathrm{CHENG}^{1,4}$, \\ KUN-HUEI YEH ${ }^{1,2,4}$, CHIH-HUNG HSU ${ }^{1,4}$ and JANG-MING LEE ${ }^{5,6}$ \\ Departments of ${ }^{1}$ Oncology, ${ }^{5}$ Surgery, and ${ }^{8}$ Medical Research, \\ National Taiwan University Hospital, Taipei, Taiwan, R.O.C.; \\ Graduate Institutes of ${ }^{2}$ Clinical Medicine and ${ }^{4}$ Oncology, and ${ }^{6}$ Department of Surgery, \\ National Taiwan University College of Medicine, Taipei, Taiwan, R.O.C.; \\ ${ }^{3}$ National Taiwan University Cancer Center, Taipei, Taiwan, R.O.C.; \\ ${ }^{7}$ Department of Internal Medicine, National Taiwan University Hospital Hsin-Chu Branch, Hsinchu, Taiwan, R.O.C.
}

\begin{abstract}
Background: The association of extended lymph node $(L N)$ dissection with improved outcomes in patients with locally advanced esophageal squamous cell carcinoma (ESCC) who received preoperative chemoradiotherapy (CRT) followed by surgery is debatable. Patients and Methods: We reviewed data from patients with esophageal cancer enrolled in three phase II clinical trials of preoperative paclitaxel and cisplatin-based CRT during 2000-2012. Patients with ESCC who underwent planned esophagectomy were enrolled. The number of resected LNs and other clinicopathological factors were analyzed regarding their impact on progression-free (PFS) and overall (OS) survival using Cox proportional hazards model. Results: In total, 139 patients were included.
\end{abstract}

Clinical trial information: NCT00154804, NCT01034189, NCT01034332.

Presented in part at the 2016 Annual Meeting of the American Society of Clinical Oncology, Chicago, June 3-7, 2016.

Correspondence to: Jang-Ming Lee, MD, Ph.D., Department of Surgery, National Taiwan University Hospital and National Taiwan University College of Medicine. No. 7, Chung-Shan South Road, Taipei, Taiwan 10002, ROC. Tel: +886 223123456 ext. 65123, Fax: +886 233933989, e-mail: jangming@ntuh.gov.tw and Chih-Hung Hsu, MD, Ph.D., Graduate Institute of Oncology, National Taiwan University College of Medicine. No.1 Section 1 Jen Ai Road, Taipei, Taiwan 10051, R.O.C. Tel: +886 223123456 ext. 67680, Fax: +886 223711174, e-mail: chihhunghsu@ntu.edu.tw

Key Words: Esophageal neoplasms, squamous cell carcinoma, combined modality therapy, lymph node dissection, prognosis.
The median PFS and OS were 24.4 and 31.8 months, respectively. The median number of resected and positive $L N s$ were 19 (range=2-96) and 0 (range=0-9), respectively. The mean number of positive LNs did not differ significantly among quartile groups of total resected LNs (quartile 1: 2-12, 2: 13-19, 3: 20-29, and 4: 30-96). The resected LN number analyzed as dichotomies divided by the median or as continuous variables was not associated with PFS or OS. However, in an exploratory analysis, patients of quartiles 2 and 3 had longer PFS and OS than those with quartiles of 1 and 4 in multivariate analysis $(p=0.019$ and 0.005 , respectively). Conclusion: Although extensive $L N$ dissection was not associated with improved survival, resection of 13-29 LNs was associated with improved survival in patients with locally advanced ESCC receiving preoperative paclitaxel and cisplatin-based CRT.

Esophageal cancer is a malignancy with high lethality. More than 450,000 new cases and more than 400,00 deaths were attributed to esophageal cancer worldwide in 2012. Esophageal adenocarcinoma (EAC) is major type of esophageal cancer in Western countries, whereas esophageal squamous cell carcinoma (ESCC) is predominant in Eastern countries (1). EAC and ESCC are distinct disease entities with different risk factors, genetic changes, and geographical distributions (2-4).

Preoperative chemoradiotherapy (CRT) followed by surgery has become one of the most commonly used treatment modalities for patients with locally advanced esophageal cancer (5-7). The Chemoradiotherapy for Oesophageal Cancer Followed by Surgery Study (CROSS) trial, a phase III study for patients with resectable esophageal 
cancer, demonstrated a significant survival benefit of preoperative paclitaxel and carboplatin-CRT followed by surgery compared to surgery alone (8). In the subgroup analysis of the CROSS trial, the median overall survival (OS) improved from 21.1 months [95\% confidence interval $(\mathrm{CI})=15.4-26.7$ months] in the group treated with surgery alone to 81.6 months (95\% CI=47.2-116.0 months) in the preoperative CRT group for patients with ESCC, with a hazard ratio (HR) of 0.48 (95\% $\mathrm{CI}=0.28-0.83)(9)$.

Studies have identified several prognostic factors, including pathological complete response (pCR), pathological stage, and microscopically free surgical margin, for patients with esophageal cancer receiving preoperative CRT $(10,11)$. The prognostic effect of the number of resected lymph nodes (LNs) on patients with esophageal cancer has been a topic of ongoing investigation. Two retrospective studies on patients with esophageal cancer undergoing surgery alone demonstrated that the number of resected LNs is an independent prognostic factor for survival $(12,13)$, and one retrospective study identified at least 15 resected LNs to be required for adequate staging for patients with esophageal cancer undergoing surgery with or without preoperative CRT (14). Another retrospective study demonstrated a higher number of resected LNs (more than 30) to be associated with best outcome for patients with esophageal cancer undergoing surgery with or without adjuvant radiotherapy (15). By contrast, a retrospective study on patients with esophageal cancer receiving preoperative CRT followed by surgery, with EAC as the predominant histology, showed the number of resected LNs not to be associated with survival (16). Two recent post hoc retrospective analyses of CROSS trial and Francophone de Cancérologie Digestive (FFCD) 9901 trial (another phase III trial evaluating preoperative CRT focusing on patients with clinical stage I and II esophageal cancer) have demonstrated that the number of resected LNs is not associated with the survival of patients with esophageal cancer receiving preoperative $\operatorname{CRT}(17,18)$. Moreover, a nationwide population-based study in Sweden indicated that more extensive lymphadenectomy during surgery for esophageal cancer does not improve survival (19).

Most of the aforementioned studies addressed the prognostic impact of the number of resected LNs in patients with esophageal cancer of both histological types, i.e. EAC and ESCC. To evaluate the prognostic impact of the number of resected LNs in patients with ESCC receiving preoperative CRT, we conducted the current study by reviewing a relatively large patient cohort treated with preoperative paclitaxel and cisplatin (TP)-based CRT followed by surgery.

\section{Patients and Methods}

Clinical trials for locoregional esophageal cancer. Between March 2000 and March 2012, three prospective phase II trials for locally advanced esophageal cancer patient cohort were conducted at the National Taiwan University Hospital (NTUH), Taipei, Taiwan. Patients enrolled in the three phase II trials were required to have locally advanced esophageal cancer with clinical stages of T3N0M0, T13N1M0, or M1a (celiac and supraclavicular lymphadenopathy for upper thoracic and lower thoracic esophageal cancer, respectively), according to the sixth edition of the American Joint Committee on Cancer (AJCC) Tumor, Node, Metastasis (TNM) staging system (20). In all three studies, patients underwent clinical staging workup through esophagogastroduodenoscopy (EGD), computed tomography (CT), endoscopic ultrasonography, and bronchoscopy. For clinical staging workup, fluorodeoxyglucose positron emission tomography was optional for one phase II trial initiated in March 2000, but mandatory in the other two studies.

The inclusion and exclusion criteria of the three phase II trials have been reported previously (21-23). Briefly, patients were required to have good performance status [Eastern Cooperative Oncology Group Performance Status (ECOG PS) of 0-2]; appropriate hematological, hepatic and renal functions; and no distant metastasis. Written informed consent had to be obtained from all participants. All three studies were approved by the Institutional Research Ethics Committee of NTUH (900603, 200707051M, and 200803088M).

Treatment and follow-up. All patients received preoperative TP-based CRT with a radiation dose of $40 \mathrm{~Gy}$ in 20 fractions, followed by esophagectomy planned 4-6 weeks after completing the preoperative CRT. Operative methods included open surgery or video-assisted thoracic surgery. No preplanned adjuvant therapy was administered.

All CRT regimens were based on the TP combination. For the first phase II trial, the TP-CRT regimen was the twice weekly administration of TP $\left(35 \mathrm{mg} / \mathrm{m}^{2}\right.$ paclitaxel on Monday and Thursday and $15 \mathrm{mg} / \mathrm{m}^{2}$ cisplatin on Tuesday and Friday) plus 40-Gy radiation in 20 fractions (21). For the second trial, the regimen included the aforementioned TP-CRT regimen along with cetuximab administered at a loading dose of $400 \mathrm{mg} / \mathrm{m}^{2}$, followed by $250 \mathrm{mg} / \mathrm{m}^{2} /$ week cetuximab in four doses (22). For the third trial, the regimen included the aforementioned TP-CRT regimen, preceded by a cycle of induction chemotherapy with TP plus 24-h infusion of high-dose 5-fluorouracil and leucovorin (TP-HDFL) (23).

Follow-up after TP-based CRT and surgery was conducted as follows: During the first 3 years, patients underwent clinical follow-up every 2-3 months and imaging studies including EGD, CT, and additional studies for symptomatic lesions every 4 months; during the fourth and fifth years, patients underwent clinical follow-up every 3 months and imaging studies every 6 months.

Cohort of this study. The patient cohort of our study was retrospectively identified from the three aforementioned phase II trials (21-23). We specifically analyzed the prognostic impact of the number of resected LNs during esophagectomy only in patients with locally advanced ESCC receiving preoperative CRT; hence from the current analysis we excluded patients who were had adenocarcinoma histology, had developed progressive disease during or after preoperative CRT, did not receive planned esophagectomy, and had initial distant metastatic disease. The seventh edition of the AJCC TNM staging system was used for pathological staging (24). The present study was approved by the Institutional Research Ethics Committee of NTUH. 


\section{TP-CRT-based therapy $(\mathrm{N}=\mathbf{2 1 5})$}

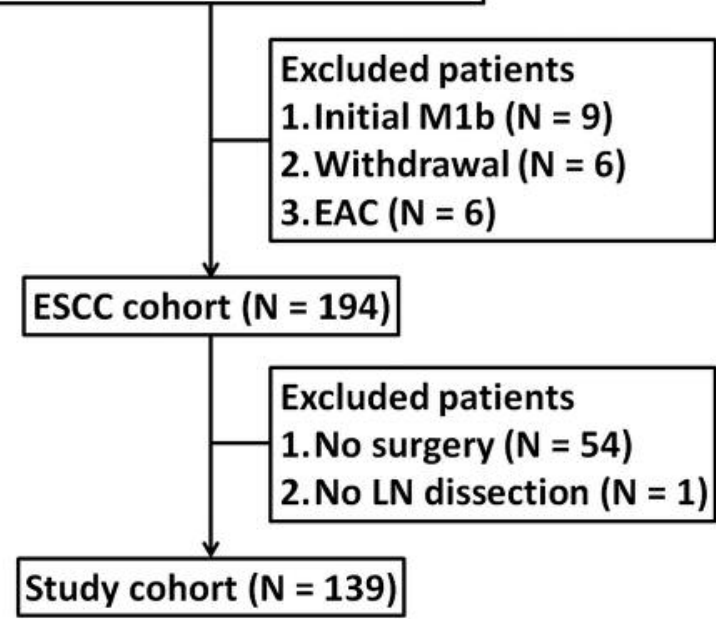

Figure 1. Study cohort. TP-based CRT: Paclitaxel and cisplatin-based chemoradiotherapy regimen; EAC: esophageal adenocarcinoma; ESCC: esophageal squamous cell carcinoma; LN: lymph node.

Statistical analysis. Follow-up data were compiled until December 31, 2015, as the cutoff date. The primary endpoint was whether the number of resected LNs predicted the prognosis of patients with locally advanced ESCC receiving preoperative TP-based CRT followed by surgery. Descriptive statistics were used for the clinicopathological characteristics. Analysis of variance (ANOVA) was used to compare the mean number of positive LNs between quartiles of the number of resected LNs. Linear regression was used to determine the correlation between the numbers of positive LNs and resected LNs. Progression-free survival (PFS) was defined from the date of enrollment to the date of progression, death from any cause, or the final follow-up date (censored). OS was defined from the date of enrollment to the date of death or final follow-up (censored). Univariate Cox proportional hazards model was used to analyze the clinicopathological factors and number of resected LNs as dichotomies divided by the median LN number of 19 or specific LN number such as 15 (14) and 23 (12), as quartiles (19), or as continuous variables (every 10 additionally resected nodes) (17) for PFS and OS according to the previously published reports. Statistically significant variables $(p \leq 0.05)$ were used for multivariate analysis by Cox proportional hazards model for PFS and OS thereafter. The survival curves were analyzed using the Kaplan-Meier (KM) method and compared with log-rank test. All data analyses were performed using SPSS version 20.0 (IBM Corp., Armonk, NY, USA).

\section{Results}

Patient characteristics. In total, 215 patients were enrolled in all three studies; 139 were included in the present study (Figure 1). The clinicopathological characteristics of the study cohort are summarized in Table I. Their median age was 53.8 (range $=34.3-74.3)$ years; $131(94.2 \%)$ patients were men, and $132(95.0 \%)$ had an ECOG PS of 0-1. The clinical
Table I. Patients clinicopathological characteristics.

\begin{tabular}{|c|c|}
\hline Clinicopathological characteristic & $(\mathrm{N}=139)$ \\
\hline Age, years $(<65 / \geq 65)$ & $123 / 16$ \\
\hline Median (range) & $53.8(34.3-74.3)$ \\
\hline Gender: Male/female & $131 / 8$ \\
\hline ECOG PS: $0-1 / 2$ & $132 / 7$ \\
\hline Clinical Ta: $2 / 3 / 4$ & $4 / 133 / 2$ \\
\hline Clinical Na: 0/1 & $8 / 131$ \\
\hline Clinical M1 a $\mathrm{a}^{\mathrm{a}}-/+$ & $129 / 10$ \\
\hline Clinical stage: IIA and IIB/III/IVA & $9 / 120 / 10$ \\
\hline Primary site: $\mathrm{C}$ and $\mathrm{U} / \mathrm{M} / \mathrm{L}$ & $38 / 68 / 33$ \\
\hline Albumin: $<4 \mathrm{~g} / \mathrm{dl} / \geq 4 \mathrm{~g} / \mathrm{dl} /$ missing & $23 / 112 / 4$ \\
\hline $\mathrm{WBC} / \mu \mathrm{l}:<10,000 / \geq 10,000 /$ missing & $109 / 26 / 4$ \\
\hline Operation method: Open/VATS & $50 / 89$ \\
\hline Median days from radiation & $44(18-98)$ \\
\hline Elective nodal irradiation: $-/+/$ missing & $26 / 110 / 3$ \\
\hline \multicolumn{2}{|l|}{ Preoperative therapy protocol: } \\
\hline TP-CRT/Cetuximab/TP-HDFL & $56 / 37 / 46$ \\
\hline Pathological Tb: 0 or Tis/1/2/3/NA & $57 / 18 / 29 / 31 / 4$ \\
\hline Pathological $\mathrm{N}^{\mathrm{b}}$ : $0 / 1 / 2 / 3$ & $100 / 26 / 12 / 1$ \\
\hline Median no. of resected lymph nodes (range) & $19(2-96)$ \\
\hline Margin: free/close ( $\leq 1 \mathrm{~mm}$ or involved) & $126 / 13$ \\
\hline Extranodal extension: Negative/positive & $124 / 15$ \\
\hline \multicolumn{2}{|l|}{ Lymphovascular or perineural invasion: } \\
\hline Negative/positive & $123 / 16$ \\
\hline pCR: No/yes & $91 / 48$ \\
\hline
\end{tabular}

aAccording to the 6th American Joint Committee on Cancer (AJCC) tumor, node, metastasis (TNM) staging system (20); baccording to 7th AJCC TNM staging system (24); C: cervical; U: upper thoracic; M: middle thoracic; L: lower thoracic; WBC: white cell count, VATS: video-assisted thoracoscopic surgery; TP-CRT: chemoradiotherapy with twice weekly paclitaxel and cisplatin; Cetuximab: cetuximab plus TPCRT; TP-HDFL: one cycle induction chemotherapy with paclitaxel and cisplatin plus 24-h infusion of high-dose 5-fluorouracil and leucovorin followed by TP-CRT; pCR: pathological complete remission (no residual invasive tumor cell in primary site and resected lymph nodes).

stage, according to the sixth edition of the AJCC TNM staging system, was stage III or IVA for most patients of this study cohort $(93.5 \%)$.

About two-thirds of the patients underwent video-assisted thoracoscopic surgery $(64.0 \%)$, whereas the remaining patients underwent open surgery. The median duration from radiation completion to surgery was 44 (range=18-98) days. R0 resection was achieved in $90.6 \%$ of the patients. Pathological staging of the resected specimens after preoperative CRT was performed according to the seventh edition of the AJCC TNM staging system. Approximately one-third of patients $(34.5 \%)$ achieved pCR, defined as no residual invasive tumor cell in primary site and dissected LNs.

Number of resected and positive LNs. The distribution of the number of resected LNs is presented in Figure 2A. The 

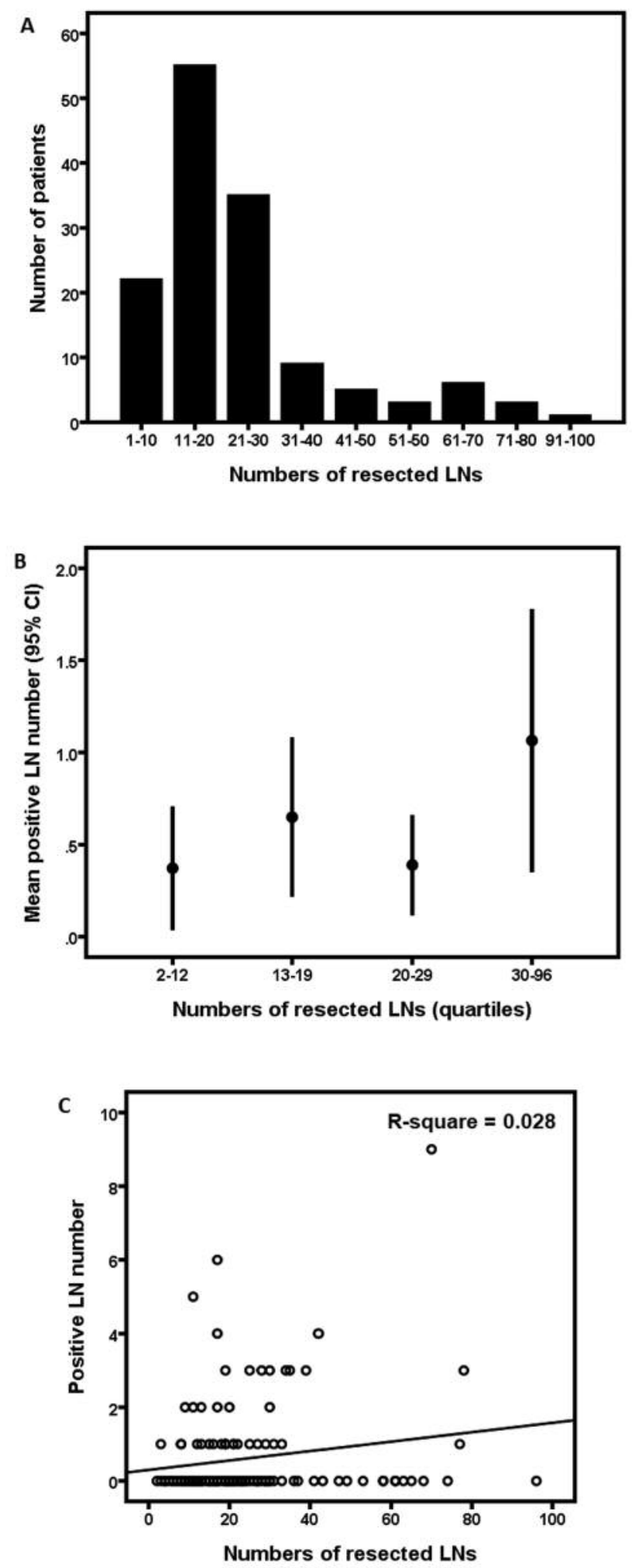

Figure 2. A: Distribution of the number of resected lymph nodes (LNs). B: Mean positive LN number [with 95\% confidence interval (CI)] in quartiles of total resected LNs. C: Association between the number of positive LNs and resected LNs through linear regression. median number of resected LNs was 19 (range=2-96). The mean numbers of positive LNs by quartiles are shown in Figure $2 \mathrm{~B}$; the numbers did not differ significantly among the four quartiles $(p=0.116)$. Linear regression revealed extremely low positive correlation between the number of positive LNs and number of resected LNs (R2 $=0.028$, Pearson correlation coefficient $=0.168, p=0.048$; Figure 2C).

Univariate analysis of the number of resected LNS and survival. The median PFS and OS of the entire study cohort were $24.4(95 \% \mathrm{CI}=16.1-32.8)$ and $31.8(95 \% \mathrm{CI}=21.2-42.4)$ months, respectively. The PFS and OS curves for the entire study cohort, assessed through the KM method, are shown in Figure 3A and B, respectively.

The univariate analysis of the association of clinicopathological factors and the number of resected LNs with PFS is summarized in Table II. Sex $(p=0.045)$, ECOG PS $(p=0.001)$, primary site $(p=0.005)$, pathological $\mathrm{T}$ $(p=0.004)$ and $\mathrm{N}(p<0.001)$ stages, extranodal extension (ENE; $p<0.001)$, and pCR $(p=0.002)$ were significant prognostic factors for PFS. The number of resected LNs was not associated with PFS no matter whether analyzed as dichotomies divided by the median, as dichotomies divided by a specific number of LNs such as 15 and $23(12,14)$, or as a continuous variable. Further analysis was conducted on the number of resected LNs divided into quartiles. The median PFS was 13.7, 39.9, 27.2, and 11.8 months for patients with number of resected LNs of quartile 1 to 4 , respectively $(p=0.123$ ) (Figure 3C). Because patients of LN quartiles 2 and 3 had numerically longer PFS than those of quartiles 1 and 4 , we thus conducted an exploratory analysis comparing quartiles 2 and 3 (LN number=13-29) as a group with quartiles 1 and 4 (LN number $<13$ and $>29$ ) as a group. It showed belonging to quartile 2 or 3 was associated with significantly better PFS in univariate analysis $(p=0.020)$ (Figure 3E).

In univariate analysis on OS, ECOG PS $(p=0.001)$, primary site $(p=0.025)$, pathological $\mathrm{N}$ stage $(p<0.001)$, $\operatorname{ENE}(p=0.011)$, and $\operatorname{pCR}(p=0.004)$ were significant prognostic factors. The number of resected LNs when analyzed as dichotomies or as continuous variables were not associated with patient OS. However, the median OS differed significantly by LNs quartile: with 20.6, 69.2, 41.2 and 19.2 months for quartiles 1 to 4 , respectively $(p=0.050)$ (Figure 3D). An additional analysis also showed that belonging to quartile 2 or 3 was statistically significantly associated with better OS in univariate analysis $(p=0.006)$ (Figure 3F).

Multivariate analysis of the number of resected LNs and survival. The clinicopathological factors that were significantly associated with PFS or OS in univariate analysis, including the number of resected LNs in quartiles (quartiles 2 and 3 versus quartiles 1 and 4), were further analyzed for their prognostic significance by multivariate 
A

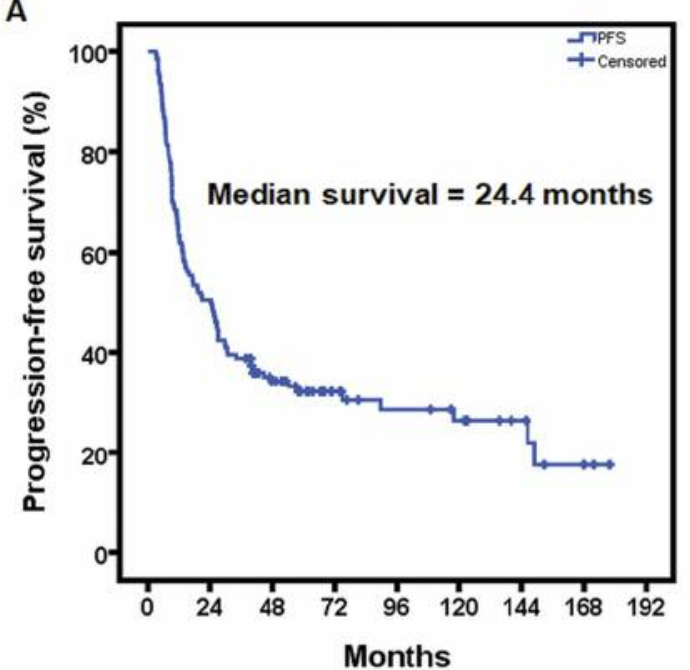

C

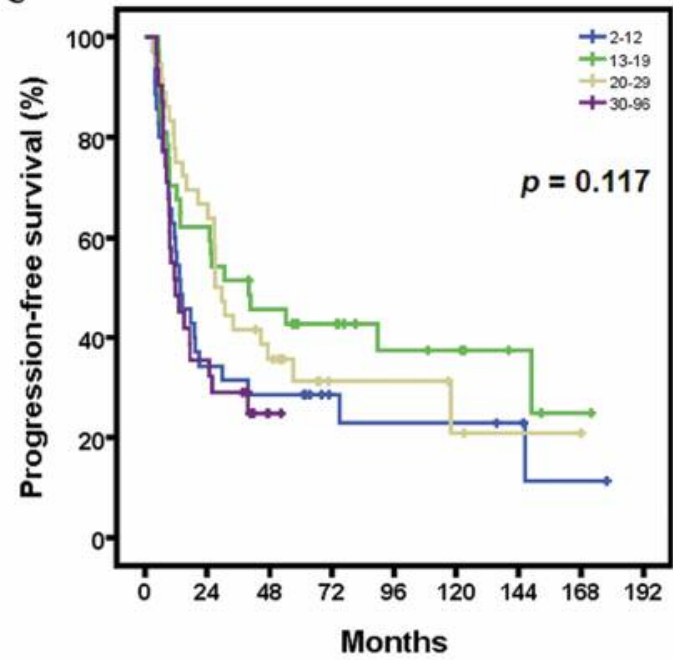

E

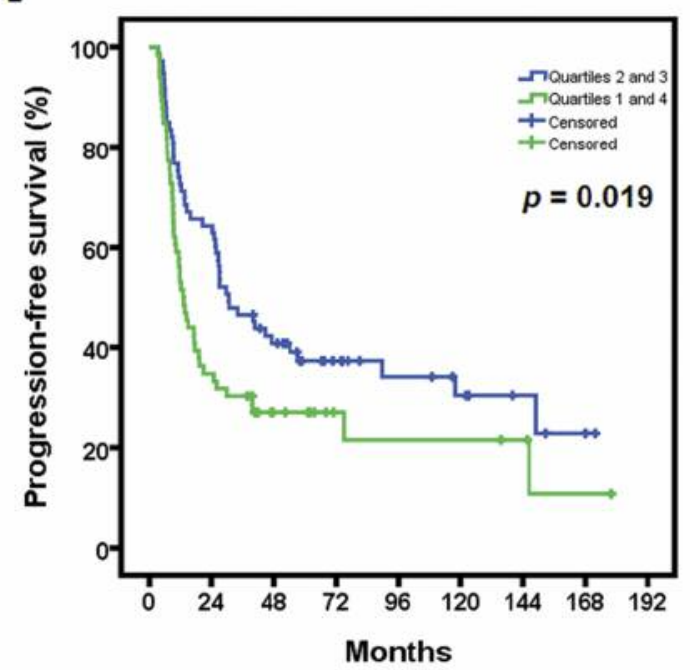

B

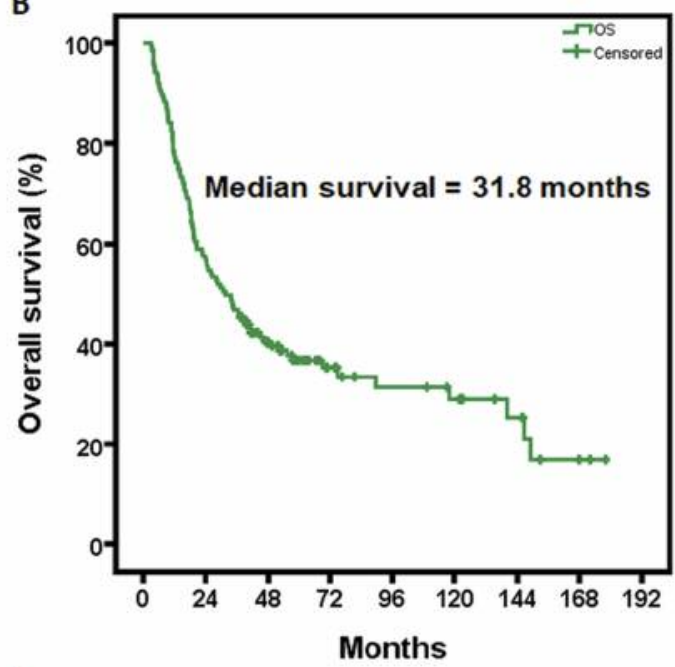

D

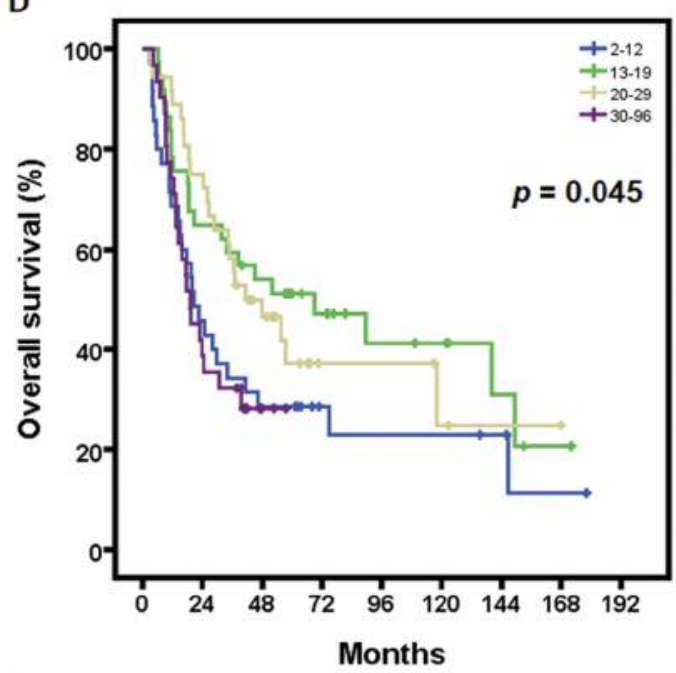

$\mathbf{F}$

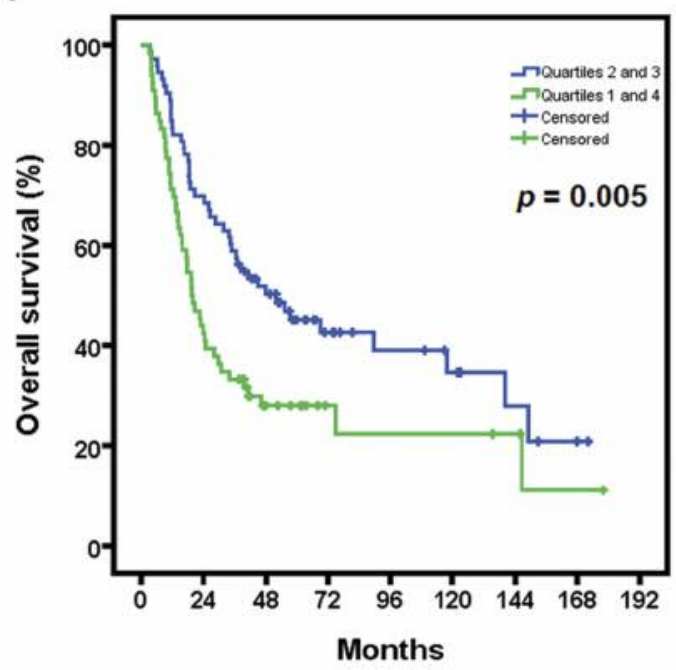

Figure 3. Kaplan-Meier method-based curves for progression-free survival $(A, C, E)$ and overall survival $(B, D, F)$ for the entire study cohort $(A$, $B)$, and according to number of resected lymph nodes as quartiles (1:2-12,2:13-19, 3:20-29, 4: 30-96) (C, D), and patients of quartiles 2 and 3 compared with quartiles 1 and $4(E, F)$. 
Table II. Univariate and multivariate analyses of progression-free survival and overall survival (Cox proportional hazards model).

\begin{tabular}{|c|c|c|c|c|c|c|c|c|c|c|c|c|}
\hline \multirow[b]{3}{*}{ Variable } & \multicolumn{6}{|c|}{ Univariate } & \multicolumn{6}{|c|}{ Multivariate } \\
\hline & \multicolumn{3}{|c|}{ Progression-free survival } & \multicolumn{3}{|c|}{ Overall survival } & \multicolumn{3}{|c|}{ Progression-free survival } & \multicolumn{3}{|c|}{ Overall survival } \\
\hline & HR & $95 \% \mathrm{CI}$ & $p$-Value & HR & $95 \% \mathrm{CI}$ & $p$-Value & HR & $95 \% \mathrm{CI}$ & $p$-Value & HR & $95 \% \mathrm{CI}$ & $p$-Value \\
\hline \multicolumn{13}{|l|}{ Gender } \\
\hline Female & 1.00 & & & 1.00 & & & 1.00 & & & 1.00 & & \\
\hline Male & 3.26 & $1.03-10.32$ & 0.045 & 2.23 & $0.81-6.08$ & 0.119 & 2.42 & $0.74-7.87$ & 0.142 & 1.59 & $0.56-4.46)$ & 0.383 \\
\hline \multicolumn{13}{|l|}{ ECOG PS } \\
\hline $0-1$ & 1.00 & & & 1.00 & & & 1.00 & & & 1.00 & & \\
\hline 2 & 3.68 & $1.68-8.07$ & 0.001 & 3.98 & $1.81-8.75$ & 0.001 & 7.12 & $2.72-18.61$ & $<0.001$ & 6.44 & $2.44-17.03$ & $<0.001$ \\
\hline Primary site & & & 0.005 & & & 0.025 & & & 0.017 & & & 0.117 \\
\hline $\mathrm{C}$ and $\mathrm{U}$ & 1.00 & & & 1.00 & & & 1.00 & & & 1.00 & & \\
\hline M & 0.47 & $0.29-0.74$ & 0.001 & 0.52 & $0.32-0.83$ & 0.007 & 0.47 & $0.28-0.79$ & 0.004 & 0.58 & $0.35-0.98$ & 0.040 \\
\hline $\mathrm{L}$ & 0.77 & $0.45-1.30$ & 0.327 & 0.71 & $0.41-1.24$ & 0.231 & 0.66 & $0.37-1.17$ & 0.154 & 0.68 & $0.37-1.25$ & 0.213 \\
\hline Pathological AJCC7th T & & & 0.004 & & & 0.113 & & & 0.049 & & & 0.130 \\
\hline 0 or Tis & 1.00 & & & 1.00 & & & 1.00 & & & 1.00 & & \\
\hline $\mathrm{T} 1$ & 1.29 & $0.68-2.44$ & 0.441 & 1.30 & $0.68-2.49$ & 0.420 & 1.25 & $0.64-2.43$ & 0.518 & 1.31 & $0.67-2.56$ & 0.427 \\
\hline $\mathrm{T} 2$ & 1.65 & $0.96-2.82$ & 0.069 & 1.48 & $0.85-2.59$ & 0.171 & 1.78 & $1.00-3.16$ & 0.051 & 1.65 & $0.90-3.04$ & 0.105 \\
\hline $\mathrm{T} 3$ & 2.07 & $1.24-3.46$ & 0.006 & 1.91 & $1.13-3.23$ & 0.016 & 2.10 & $1.21-3.67$ & 0.009 & 1.94 & $1.10-3.42$ & 0.023 \\
\hline Pathological AJCC7th N & & & $<0.001$ & & & $<0.001$ & & & 0.130 & & & 0.026 \\
\hline 0 & 1.00 & & & 1.00 & & & 1.00 & & & 1.00 & & \\
\hline $\mathrm{N} 1$ & 1.52 & $0.92-2.52$ & 0.101 & 1.22 & $0.71-2.09$ & 0.471 & 1.00 & $0.52-1.92$ & 0.987 & 0.82 & $0.41-1.64$ & 0.567 \\
\hline N2 & 3.77 & $2.00-7.09$ & $<0.001$ & 4.09 & $2.16-7.74$ & $<0.001$ & 2.33 & $1.11-4.87$ & 0.025 & 2.75 & $1.30-5.79$ & 0.008 \\
\hline N3 & 7.18 & $0.96-53.66$ & 0.055 & 9.88 & $1.30-75.06$ & 0.027 & 0.95 & $0.10-8.65$ & 0.961 & 2.34 & $0.25-22.14$ & 0.458 \\
\hline \multicolumn{13}{|l|}{ Extranodal extension } \\
\hline Negative & 1.00 & & & 1.00 & & & 1.00 & & & 1.00 & & \\
\hline Positive & 3.30 & $1.87-5.81$ & $<0.001$ & 2.22 & $1.20-4.12$ & 0.011 & 3.33 & $1.51-7.34$ & 0.003 & 2.04 & $0.86-4.80$ & 0.104 \\
\hline \multicolumn{13}{|c|}{$\begin{array}{llll}1.01-5.01 & -0.001 & 2.22 & 1.20-4.12\end{array}$} \\
\hline Yes & 1.00 & & & 1.00 & & & & & & & & \\
\hline No & 2.02 & $1.28-3.16$ & 0.002 & 2.00 & $1.25-3.19$ & 0.004 & & & & & & \\
\hline \multicolumn{13}{|l|}{$\begin{array}{l}\text { No. of resected LNs } \\
\text { (median) }\end{array}$} \\
\hline$<19$ & 1.00 & & & 1.00 & & & & & & & & \\
\hline$\geq 19$ & 1.12 & $0.75-1.68$ & 0.578 & 1.01 & $0.67-1.54$ & 0.949 & & & & & & \\
\hline \multicolumn{2}{|l|}{ No. of resected LNs } & $0.91-116$ & 0702 & 103 & $090-117$ & 0664 & & & & & & \\
\hline \multicolumn{13}{|l|}{ No. of resected LNs } \\
\hline (by quartile) & & & 0.123 & & & 0.050 & & & & & & \\
\hline 1 & 1.00 & & & 1.00 & & & & & & & & \\
\hline 2 & 0.62 & $0.35-1.08$ & 0.088 & 0.56 & $0.32-0.99$ & 0.047 & & & & & & \\
\hline 3 & 0.71 & $0.41-1.22$ & 0.209 & 0.62 & $0.35-1.09$ & 0.097 & & & & & & \\
\hline 4 & 1.14 & $0.65-2.00$ & 0.653 & 1.12 & $0.63-1.99$ & 0.689 & & & & & & \\
\hline \multicolumn{13}{|l|}{ No. of resected LNs } \\
\hline Quartiles 2 and 3 & 1.00 & & & 1.00 & & & 1.00 & & & 1.00 & & \\
\hline Quartiles 1 and 4 & 1.60 & $1.08-2.39$ & 0.020 & 1.78 & $1.18-2.68$ & 0.006 & 1.83 & $1.16-2.89$ & 0.009 & 1.83 & $1.15-2.92$ & 0.011 \\
\hline
\end{tabular}

ECOG PS: Eastern Cooperative Oncology Group Performance Status; AJCC: American Joint Committee on Cancer (24); C: cervical, U: upper thoracic, M: middle thoracic, L: lower thoracic; pCR: pathological complete remission (no residual invasive tumor cell in primary site and resected lymph nodes); LNs: lymph nodes. LN quartiles: 1: 2-12, 2: 13-19, 3: 20-29, 4: 30-96.

analysis. We found that ECOG PS $(p<0.001)$, primary site $(p=0.017)$, pathological T stage $(p=0.049)$, ENE $(p=0.003)$, and the number of resected LNs in quartiles (quartiles 2 and 3 versus quartiles 1 and 4$)(p=0.009)$ were significant independent prognostic factors for PFS. We also found
ECOG PS $(p<0.001)$, pathological $\mathrm{N}$ stage $(p=0.026)$, and the number of resected LNs in quartiles (quartiles 2 and 3 versus quartiles 1 and 4) $(p=0.011)$ were significant independent prognostic factors for OS. The results of multivariate analysis are summarized in Table II. 


\section{Discussion}

The prognostic impact of extended lymphadenectomy in patients with esophageal cancer remains debatable (25). In the current retrospective study, we analyzed a large ESCC patient cohort from three clinical studies and found that extended lymphadenectomy is not associated with the prognosis of patients with locally advanced ESCC receiving preoperative TP-based CRT followed by esophagectomy. Our findings corroborate those of recent post hoc analyses of the CROSS and FFCD 9901 trials, two randomized trials for preoperative CRT in patients with resectable esophageal cancer $(17,18)$. Thus, preoperative CRT may obviate the benefits of extended lymphadenectomy that has been demonstrated in esophageal cancer patients undergoing surgery alone.

However, in an exploratory analysis of the current study, we demonstrated that patients of $\mathrm{LN}$ quartiles 2 and 3 had a more favorable prognosis than those of quartiles 1 and 4 did. Our data showing that patients with fewer than 13 resected LNs had inferior survival are in line with most treatment guidelines supporting that suboptimal lymphadenectomy is not preferred. On the other hand, our data showing that patients with more than 29 resected LNs also had inferior survival imply that the prognostic benefit of extensive lymphadenectomy may plateau at certain level and even be counteracted by other poor prognostic factors associated with extended LN dissection. This inferior OS associated with extensive lymphadenectomy may be the result of the increment of postoperative complications $(25,26)$, but our data did not show this trend (data not shown). Another potential cause may be that extensive lymphadenectomy is potentially associated with far-advanced locoregional diseases at diagnosis (27).

In the present study, the number of positive LNs, classified as pathological $\mathrm{N}$ stage, demonstrated a significant effect on the survival of our patients with ESCC receiving preoperative CRT. This result is consistent with several previous reports, including ours, demonstrating that pathological N-positivity or higher pathological N-stage status is a poor prognostic factor for patients with esophageal cancer receiving preoperative CRT. It also corroborates the results of the post hoc analyses of the CROSS and FFCD 9901 trials $(17,18,28)$.

In the analysis of the CROSS trial, more extensive lymphadenectomy was associated with a higher number of positive LNs in the group who underwent surgery alone; by contrast, this association was not observed in the preoperative CRT group (17). Our study, which focused only on patients with ESCC who were receiving preoperative CRT, revealed no significant differences in the mean number of positive LNs by quartile of resected LNs (ANOVA, $p=0.116$ ). Linear regression showed a very low positive correlation, with the corresponding low $R^{2}$ value (0.028), and the Pearson correlation coefficient was only
0.168 . In other words, only $2.8 \%$ of the positive LNs could be explained by the number of LNs resected, rendering the clinical significance irrelevant.

This study has several limitations. Firstly, it was a retrospective analysis based on three consecutive clinical studies conducted at a single center. Although the three studies employed TP-based CRT as the backbone of the preoperative treatment for ESCC, the preoperative CRT regimens for the three trials varied. There was an association of CRT regimen with the number of resected LNs, i.e. the latest conducted TPHDFL followed by TP-CRT regimen was associated with increased extent of LN dissection; however, the CRT regimens did not have impact on patient survival. Secondly, the enrollment period of the study cohort was long (March 2000March 2012). During this period, diagnostic procedures, radiation therapy, surgical techniques, and postoperative care for patients with cancer have improved substantially. These differences may have subtly affected the analysis in this retrospective study. Thirdly, our analysis did not consider the extent of locoregional disease at diagnosis. For example, the dimensions of the primary esophageal tumor and extensive LN involvement identified during staging workup may have affected the surgeons' plan for extended lymphadenectomy.

This retrospective analysis found that extended lymphadenectomy was not associated with improved prognosis in patients with locally advanced ESCC receiving preoperative CRT followed by esophagectomy. However, an exploratory analysis identified that resection of 13-29 LNs was associated with improved survival in our studied patient cohort. Future studies are warranted to establish the optimal extent of lymphadenectomy in patients with locally advanced ESCC receiving preoperative CRT.

\section{Funding}

This work was supported by Grants of MOST 103-2314-B-002-092and MOST 104-2314-B-002-111- from the Ministry of Science and Technology, R.O.C. (principal investigator, Dr. Chih-Hung Hsu), and a grant from the National Taiwan University Hospital, Taipei, Taiwan, R.O.C. (NTUH 105-N3333, principal investigator, Dr. Jhe-Cyuan Guo).

\section{Acknowledgements}

Authors thank the staff in Department of Medical Research, NTUH, Taiwan.

\section{References}

1 Torre LA, Bray F, Siegel RL, Ferlay J, Lortet-Tieulent J and Jemal A: Global cancer Statistics, 2012. CA Cancer J Clin 65: 87-108, 2015.

2 Bandla S, Pennathur A, Luketich JD, Beer DG, Lin L, Bass AJ, Godfrey TE and Litle VR: Comparative genomics of esophageal adenocarcinoma and squamous cell carcinoma. Ann Thorac Surg 93: 1101-1116, 2012. 
3 Agrawal N, Jiao Y, Bettegowda C, Hutfless SM, Wang Y, David S, Cheng Y, Twaddell WS, Latt NL, Shin EJ, Wang LD, Wang L, Yang W, Velculescu VE, Vogelstein B, Papadopoulos N, Kinzler KW and Meltzer SJ: Comparative genomic analysis of esophageal adenocarcinoma and squamous cell carcinoma. Cancer Discov 2: 899-905, 2012.

4 The Cancer Genome Atlas Research Network: Integrated genomic characterization of oesophageal carcinoma. Nature 541: 169-175, 2017.

5 Pennathur A, Gibson MK, Jobe BA and Luketich JD: Oesophageal carcinoma. Lancet 381: 400-412, 2013.

6 Cooper JS, Guo MD, Herskovic A, Macdonald JS, Martenson JA Jr, Al-Sarraf M, Byhardt R, Russell AH, Beitler JJ, Spencer S, Asbell SO, Graham MV and Leichman LL: Chemoradiotherapy of locally advanced esophageal cancer: long-term follow-up of a prospective randomized trial (RTOG 85-01). Radiation Therapy Oncology Group. JAMA 281: 1623-1627, 1999.

7 Sjoquist KM, Burmeister BH, Smithers BM, Zalcberg JR, Simes RJ, Barbour A, Gebski V and Australasian Gastro-Intestinal Trials Group: Survival after neoadjuvant chemotherapy or chemoradiotherapy for resectable oesophageal carcinoma: an updated meta-analysis. Lancet Oncol 12: 681-692, 2011.

8 van Hagen P, Hulshof MC, van Lanschot JJ, Steyerberg EW, van Berge Henegouwen MI, Wijnhoven BP, Richel DJ, Nieuwenhuijzen GA, Hospers GA, Bonenkamp JJ, Cuesta MA, Blaisse RJ, Busch OR, ten Kate FJ, Creemers GJ, Punt CJ, Plukker JT, Verheul HM, Spillenaar Bilgen EJ, van Dekken H, van der Sangen MJ, Rozema T, Biermann K, Beukema JC, Piet AH, van Rij CM, Reinders JG, Tilanus HW, van der Gaast A and CROSS Group: Preoperative chemoradiotherapy for esophageal or junctional cancer. N Engl J Med 366: 2074-2084, 2012.

9 Shapiro J, van Lanschot JJ, Hulshof MC, van Hagen P, van Berge Henegouwen MI, Wijnhoven BPL, van Laarhoven HWM, Nieuwenhuijzen GAP, Hospers GAP, Bonenkamp JJ, Cuesta MA, Blaisse RJB, Busch ORC, Ten Kate FJW, Creemers GM, Punt CJA, Plukker JTM, Verheul HMW, Bilgen EJS, van Dekken H, van der Sangen MJC, Rozema T, Biermann K, Beukema JC, Piet AHM, van Rij CM, Reinders JG, Tilanus HW, Steyerberg EW, van der Gaast A and CROSS study group: Neoadjuvant chemoradiotherapy plus surgery versus surgery alone for oesophageal or junctional cancer (CROSS): long-term results of a randomised controlled trial. Lancet Oncol 16: 1090-1098, 2015.

10 Berger AC, Farma J, Scott WJ, Freedman G, Weiner L, Cheng JD, Wang H and Goldberg M: Complete response to neoadjuvant chemoradiotherapy in esophageal carcinoma is associated with significantly improved survival. J Clin Oncol 23: 4330-4337, 2005.

11 Guo JC, Huang TC, Lin CC, Hsieh MS, Chang CH, Huang PM, Lee JM, Hsu FM, Chia-Hsien Cheng J, Wang HP, Yeh KH, Cheng AL and Hsu $\mathrm{CH}$ : Postchemoradiotherapy pathologic stage classified by the American Joint Committee on the Cancer Staging System predicts prognosis of patients with locally advanced esophageal squamous cell carcinoma. J Thorac Oncol 10: 1481-1489, 2015.

12 Peyre CG, Hagen JA, DeMeester SR, Altorki NK, Ancona E, Griffin SM, Hölscher A, Lerut T, Law S, Rice TW, Ruol A, van Lanschot JJ, Wong J and DeMeester TR: The number of lymph nodes removed predicts survival in esophageal cancer: An international study on the impact of extent of surgical resection. Ann Surg 248: 549-556, 2008.
13 Rizk NP, Ishwaran H, Rice TW, Chen LQ, Schipper PH, Kesler KA, Law S, Lerut TE, Reed CE, Salo JA, Scott WJ, Hofstetter WL, Watson TJ, Allen MS, Rusch VW and Blackstone EH: Optimum lymphadenectomy for esophageal cancer. Ann Surg 251: 46-50, 2010.

14 Mariette C, Piessen G, Briez N and Triboulet JP: The number of metastatic lymph nodes and the ratio between metastatic and examined lymph nodes are independent prognostic factors in esophageal cancer regardless of neoadjuvant chemoradiation or lymphadenectomy extent. Ann Surg 247: 365-371, 2008.

15 Schwarz ER and Smith DD: Clinical impact of lymphadenectomy extent in resectable esophageal cancer. J Gastrointest Surg 11: 1384-1393, 2007.

16 Shridhar R, Hoffe SE, Almhanna K, Weber JM, Chuong MD, Karl RC and Meredith K: Lymph node harvest in esophageal cancer after neoadjuvant chemoradiotherapy. Ann Surg Oncol 20: 3038-3043, 2013.

17 Koen Talsma A, Shapiro J, Looman CW, van Hagen P, Steyerberg EW, van der Gaast A, van Berge Henegouwen MI, Wijnhoven BP, van Lanschot JJ; CROSS Study Group, Hulshof MC, van Laarhoven HW, Nieuwenhuijzen GA, Hospers GA, Bonenkamp JJ, Cuesta MA, Blaisse RJ, Busch OR, ten Kate FJ, Creemers GJ, Punt CJ, Plukker JT, Verheul HM, van Dekken H, van der Sangen MJ, Rozema T, Biermann K, Beukema JC, Piet AH, van Rij CM, Reinders JG and Tilanus HW: Lymph node retrieval during esophagectomy with and without neoadjuvant chemoradiotherapy. Ann Surg 260: 786-793, 2014.

18 Robb WB, Dahan L, Mornex F, Maillard E, Thomas PA, Meunier B, Boige V, Pezet D, Le Brun-Ly V, Bosset JF, Mabrut JY, Triboulet JP, Bedenne L, Seitz JF, Mariette C; Fédération Française de Cancérologie Digestive, Société Française de Radiothérapie Oncologique, Union des Centres de Lutte Contre le Cancer, Groupe Coopérateur Multidisciplinaire en Oncologie, French EsoGAstric Tumour working group and Fédération de Recherche En Chirurgie: Impact of neoadjuvant chemoradiation on lymph node status in esophageal cancer. Ann Surg 261: 902908, 2015.

19 van der Schaaf M, Johar A, Wijnhoven B, Lagergren P and Lagergren J: Extent of lymph node removal during esophageal cancer surgery and survival. J Natl Cancer Inst 107: djv043, 2015.

20 Greene FL, Page DL, Fleming ID, Fritz AG, Balch CM, Haller DG and Morrow M: AJCC Cancer Staging Manual. 6th ed, New York, Springer, 2002.

21 Lin CC, Hsu CH, Cheng JC, Wang HP, Lee JM, Yeh KH, Yang $\mathrm{CH}$, Lin JT, Cheng AL and Lee YC: Concurrent chemoradiotherapy with twice weekly paclitaxel and cisplatin followed by esophagectomy for locally advanced esophageal cancer. Ann Oncol 18: 93-98, 2007.

22 Lin CC, Hsu CH, Cheng JC, Yen CC, Shiah HS, Huang TC, Chen WW, Wang HP, Yeh KH, Lee JM and Cheng AL: Concurrent chemoradiotherapy with cetuximab plus twiceweekly paclitaxel and cisplatin followed by esophagectomy for locally advanced esophageal squamous cell carcinoma. J Clin Oncol 31: 4099, 2013.

23 Huang TC, Lin CC, Tzen KY, Wu YC, Cheng JC, Lee JM, Wang HP, Huang PM, Hsu FM, Yeh KH, Cheng AL and Hsu CH: A phase II study of early FDG-PET evaluation after one-cycle chemotherapy in patients with locally advanced esophageal squamous cell carcinoma treated with neoadjuvant chemoradiotherapy: Final report. J Clin Oncol 35: 4042, 2017. 
24 Edge S, Byrd DR, Compton CC, Fritz AG, Greene F and Trotti A: AJCC Cancer Staging Manual Seventh Edition New York, Springer, 2010.

25 Nishihira T, Hirayama K and Moris S: A prospective randomized trial of extended cervical and superior mediastinal lymphadenectomy for carcinoma of the thoracic esophagus. Am J Surg 175: 47-51, 1998.

26 Hulscher JB, van Sandick JW, de Boer AG, Wijnhoven BP, Tijssen JG, Fockens P, Stalmeier PF, ten Kate FJ, van Dekken $\mathrm{H}$, Obertop H, Tilanus HW and van Lanschot JJ: Extended transthoracic resection compared with limited transhiatal resection for adenocarcinoma of the esophagus. N Engl J Med 347: 1662-1669, 2002.
27 Noordman BJ and van Lanschot JJ: Gastrointestinal cancer: Effect of lymphadenectomy on survival in oesophageal cancer. Nat Rev Clin Oncol 12: 315-316, 2015.

28 Rizk NP, Seshan VE, Bains MS, Ilson DH, Minsky BD, Tang L and Rusch VW: Prognostic factors after combined modality treatment of squamous cell carcinoma of the esophagus. J Thorac Oncol 2: 1117-1123, 2007.

Received December 3, 2017

Revised January 18, 2018

Accepted January 23, 2018 